Doi: 10.4274/jus.2018.05.026

\title{
Re: Evaluation of the Azoospermic Male: A Committee Opinion
}

Practice Committee of the American Society for Reproductive Medicine in Collaboration with the Society for Male Reproduction and Urology:

Hwang K, Smith JF, Coward RM, Penzias A, Bendikson K, Butts S, Coutifaris C, Falcone T, Fossum G, Gitlin S, Gracia C, Hansen K, Jindal S, La Barbera A, Mersereau J, Odem R, Paulson R, Pfeifer S, Pisarska M, Rebar R, Reindollar R, Rosen M, Sandlow J, Stovall D, Vernon M

American Society for Reproductive Medicine, Birmingham, Alabama

Fertil Steril. 2018;109:777-782. doi: 10.1016/j.fertnstert.2018.01.043.

\section{EDITORIAL COMMENT}

Azoospermia, affecting approximately $1 \%$ of all men, is a definition for no sperm in the centrifuged pellet of two separate semen samples. Approximately 10-15\% of all infertile men receive the diagnosis of azoospermia. In this document, the Practice Committee of the American Society for Reproductive Medicine in collaboration with the Society for Male Reproduction and Urology published a very useful updated guideline for physicians who are mostly dealing with azoospermic men. The committee emphasized the importance of genetic evaluation in nonobstructive azoospermic patients and in those having no vas deferens. To my opinion, urologists working close to in vitro fertilization clinics should have more information regarding evaluation and genetic tests in azoospermic men and this document will be helpful for them.

Emre Bakırcıoğlu, MD

๑Copyright 2018 by the Association of Urological Surgery / Journal of Urological Surgery published by Galenos Publishing House. 